\title{
Stingray Envenomation of the Foot: A case report
}

\author{
by $\mathrm{Al}$ Kline, $\mathrm{DPM}^{1} \triangle$
}

The Foot \& Ankle Journal 1 (6): 4

Stingrays are docile marine animals that only strike their victim when provoked or startled. Lower extremity and foot envenomation is common when fishing in shallow waters off the beach. The stingray tail has a sharp, serrated barb along the proximal third of the tail that is usually hidden and encased in an integumentary sheath and can deliver painful enzymes causing tissue necrosis. Immediate treatment including rapid cleansing and heat submersion of the foot is recommended after injury. If treatment is delayed, infection from marine bacteria often requires hospitalization including intravenous antibiotics and surgical treatment.

Key words: Stingray envenomation

Accepted: May 2008 Published: June 2008

This is an Open Access article distributed under the terms of the Creative Commons Attribution License. It permits unrestricted use, distribution, and reproduction in any medium, provided the original work is properly cited. (The Foot \& Ankle Journal (www.faoj.org)

Stingray envenomation of the foot is a common marine injury. There is an estimated 1500 stingray injuries reported annually in the United States. ${ }^{1}$ Usually, a person will be fishing in shallow water and accidentally step on the stingray. This causes an instinctive, defense mechanism of the stingray. The tail will lash upward like a scorpion and penetrate a sharp bard in the lower extremity or foot. The stingray tail has a sharp, serrated barb along the proximal third of the tail that is usually hidden and encased in an integumentary sheath. The stinger barb is made of cartilage and the serrations are directed proximally.

Address correspondence to: Al Kline, DPM

3130 South Alameda, Corpus Christi, Texas 78404.

${ }^{1}$ Adjunct Clinical Faculty, Barry University School of Podiatric Medicine. Private practice, Chief of Podiatry, Doctors Regional Medical Center. Corpus Christi, Texas, 78411.
This means, that as the barb penetrates, the barb can rip tissue or even lacerate tendons, ligaments and other soft tissue as it pulls away from the puncture site. (Fig. 1) The integumentary sheath that encases the barb also contains a venomous protein that is released into a wound when the barb strikes and the sheath ruptures. This will cause intense pain and tissue necrosis. The barb can remain or break off in the wound. Fortunately, this only occurs in about $5 \%$ of reported cases. ${ }^{2,6}$

Envenomation occurs in up to $75 \%$ of reported stingray injuries. ${ }^{6}$ The stingray venom contains the neurotransmitter serotonin and two enzymes; 5-nucleotidase, and phosphodiesterase. ${ }^{2}$ Serotonin is responsible for the intense pain associated with the sting and the 5-nucleotidase and phosphodiesterase enzymes cause intense tissue necrosis. 


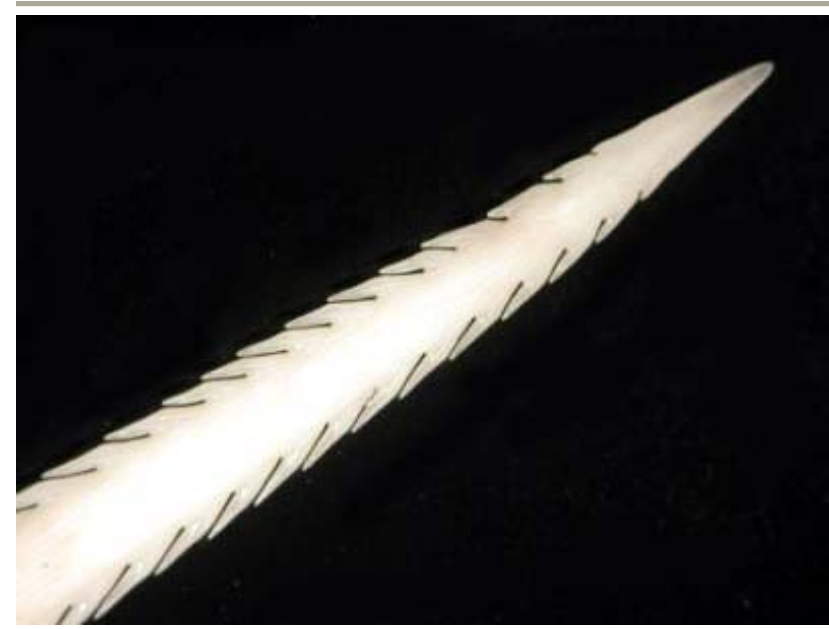

Figure 1 The serrated stingray barb. The barb is encased in an integumentary sheath. The serrated spines are directed proximally and can cause extensive tissue damage when pulled from a wound.

Fatal envenomation is extremely rare and has recently come to light due to the death of "The Crocodile Hunter", Steve Irwin, on September $4^{\text {th }}$, 2006. Steve Irwin was snorkeling in water and swam close to an Australian bull ray. (Fig. 2) The ray was startled and lashed its tail upward and pierced Steve Irwin's heart. He died shortly after pulling the barb from his chest. It was reported at that time that only three fatal envenomations in Australia's history had been reported before Irwin's death.

Interestingly, one month later in October 2006, James Bertikas from Florida was stung by a ray as the barb also pierced his heart. However, he did not remove the barb, and survived his injury. In his case, a $2 \frac{1}{2}$ inch barb penetrated his left lung and migrated into his heart crossing both the left and right ventricle. ${ }^{8}$ Most deaths occur from the actual laceration of a major artery or organ such as the heart from the barb and not the venomous effects.

However, in one report, a 12 year old boy died after envenomation from a freak accident when an 'airborne' ray slammed against his chest penetrating the barb into the boys left lung and piercing the pericardium.

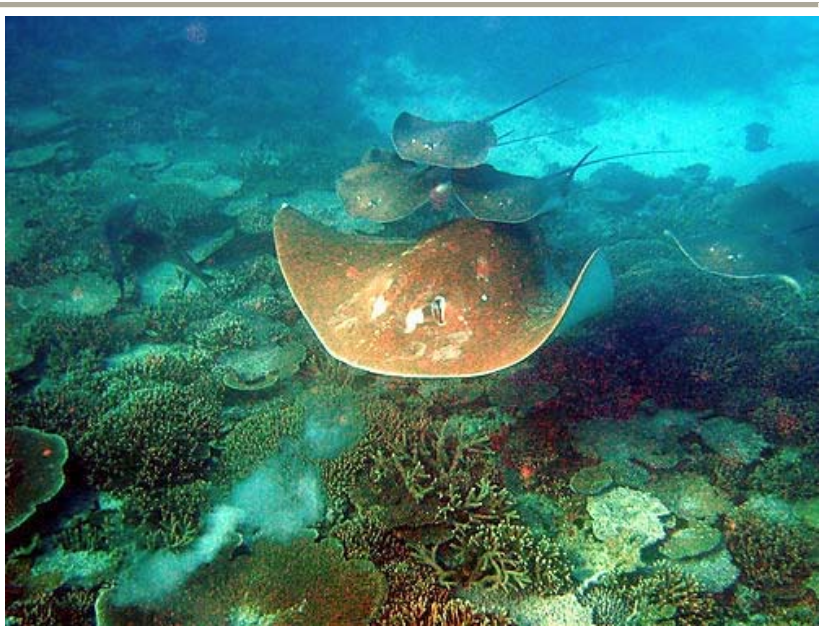

Figure 2 The Australian bull ray or Southern eagle ray (Myliobatis australis).

The boy was relatively asymptomatic and initially treated for a puncture wound to the chest and knee, but he died six days later from sequestered venom and myocardial necrosis causing right ventricular rupture and fatal cardiac tamponade. ${ }^{2,6}$ Another reported case involved a man who sustained a laceration to his femoral artery and bled to death. ${ }^{2}$ In most cases, stingray injuries are not life-threatening, but can cause long-term complications. In one report, osteomyelitis of the malleolus resulted from an ankle strike seven months after injury. ${ }^{6}$

The effects of envenomation are not clearly understood as to reported systemic effects. Common reported symptoms can include diaphoresis, nausea, cardiac arrhythmias,tremors, skin rash, headache,delirium, fever, hypertension, syncope, anxiety and a host of other common allergic reactions.

Another complication from injury is the seawater and bacteria that can enter a wound on penetration during this injury.

We present the case of a 31 year old male who stepped on a stingray while fishing. He delayed initial treatment, continued to fish and developed cellulitis with a painful foot which required hospitalization and surgical treatment. 


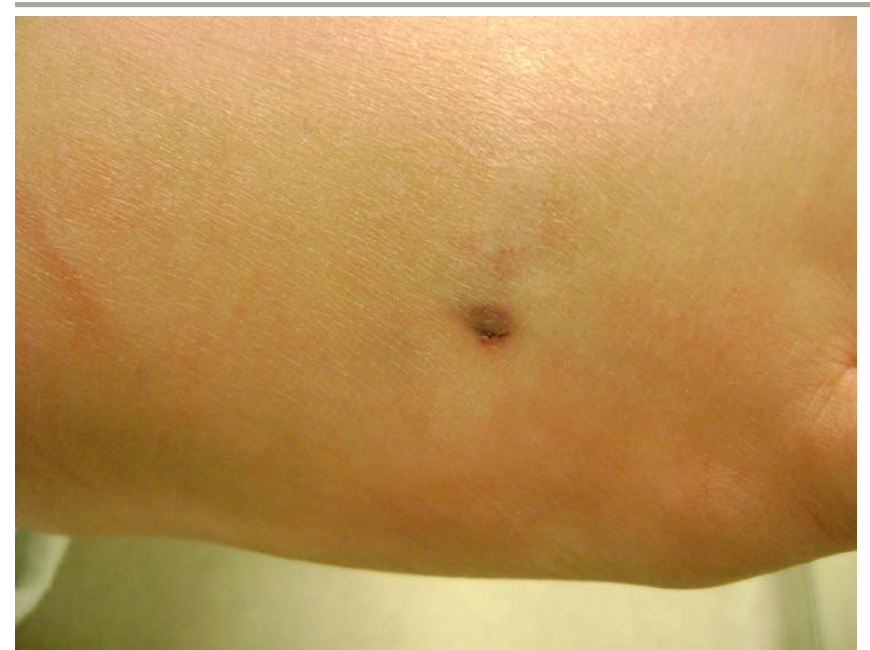

Figure 3 A small puncture wound is see to the dorsolateral aspect of the foot consistent with a stingray envenomation. The central puncture wound will have signs of tissue necrosis.

\section{Case Report}

A 31 year-old male presented to the emergency room with a hot, swollen foot. He was fishing in shallow water the day before and was stung by a stingray. He felt a sharp pain to the top of his foot. He continued to fish most of the day. In the evening, his foot swelling and pain got progressively worse. His wife went to the internet and realized that submerging the foot in hot water would eliminate the pain. He submerged the foot in water and his pain dissipated that evening. In the morning, he had a progressive increase in pain and presented to the emergency room for treatment.

Clinical evaluation revealed a small puncture wound to the dorsolateral aspect of the right foot. (Fig. 3) There was increased soft tissue swelling with slight tissue crepitus. His laboratory data revealed a 16,000 white count with a left shift. Routine radiographic evaluation showed an area of gas in the region of the puncture wound, but no sign of barb. (Fig. 4)

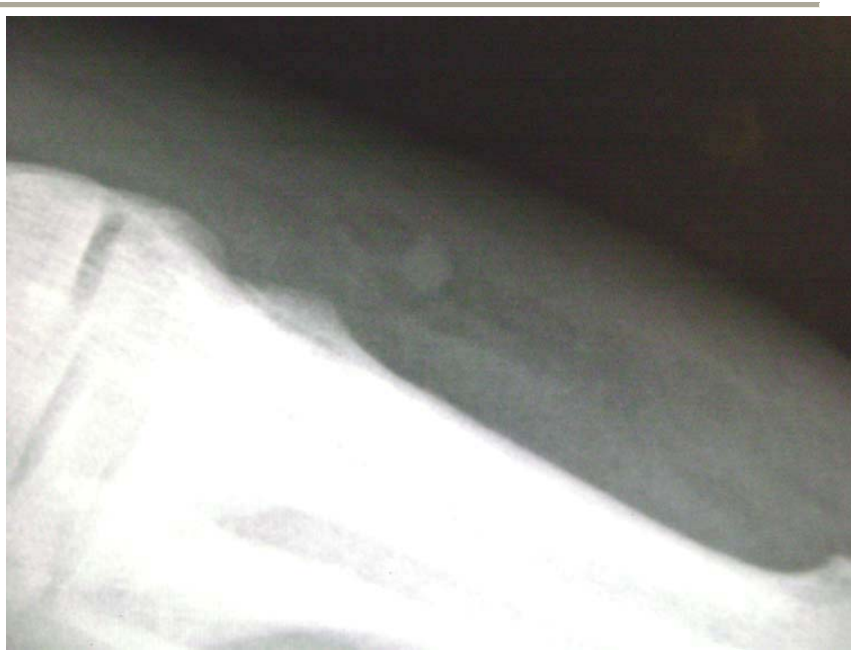

Figure 4 Radiographic evaluation reveals soft tissue gas formation in the subcutaneous tissues of the dorsal foot. No barb is seen on radiograph.

It was recommended he go directly to the operating room for incision and drainage with exploration of the wound.

Surgical exploration revealed soft tissue necrosis through the subcutaneous layer from the initial envenomation. All soft tissue was removed and sent for deep tissue culture. Some local debris was flushed from the wound, but no barb was located. The wound was thoroughly irrigated with Betadine solution and Bacitracin irrigation. The wound was then loosely packed and the edges of the incision were loosely approximated. (Fig. 5)

Tissue cultures revealed Staphylococcus aureus. He was placed on IV Levaquin. His initial infection took about a week to resolve and he was discharged from the hospital. He continued local wound care and within 2 weeks of his injury, the wound closed. (Fig. 6) 


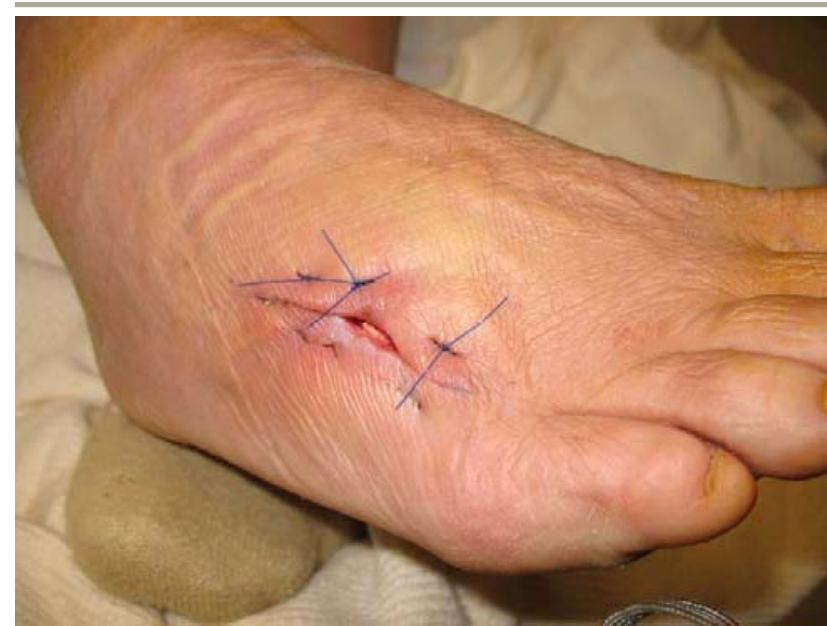

Figure 5 It is important to open the puncture site and remove any necrotic tissue and explore for foreign material that may cause continued infection. Necrotic tissue is removed, the edges of the wound can be loosely approximated and the central injury point may granulate and heal by secondary intention.

\section{Discussion}

It is important to initially submerge the foot into hot water after the incident. Rapid application of heat will denature the enzymes causing the pain and limit the effects of tissue necrosis. It is recommended that immediate submersion into hot, but not scalding, water will also help to ease the pain of this injury.

It is recommended to submerge the foot into a water temperature of 42 to 45 degrees Celsius (108-113 degrees Fahrenheit) for 30 to 90 minutes, or until the pain resolves. ${ }^{3}$ Infection of the wound can usually be avoided with aggressive wound cleansing and oral antibiotics.

In cases where cellulites results in delayed treatment or is not responsive to oral antibiotics, hospitalization and intravenous antibiotics is recommended. The most common pathogens to infect the wound include Staphylococcus aureus and streptococcus species. Water-borne pathogens of concern include Vibrios vulnificans in salt water and Aeromonas species in fresh water.

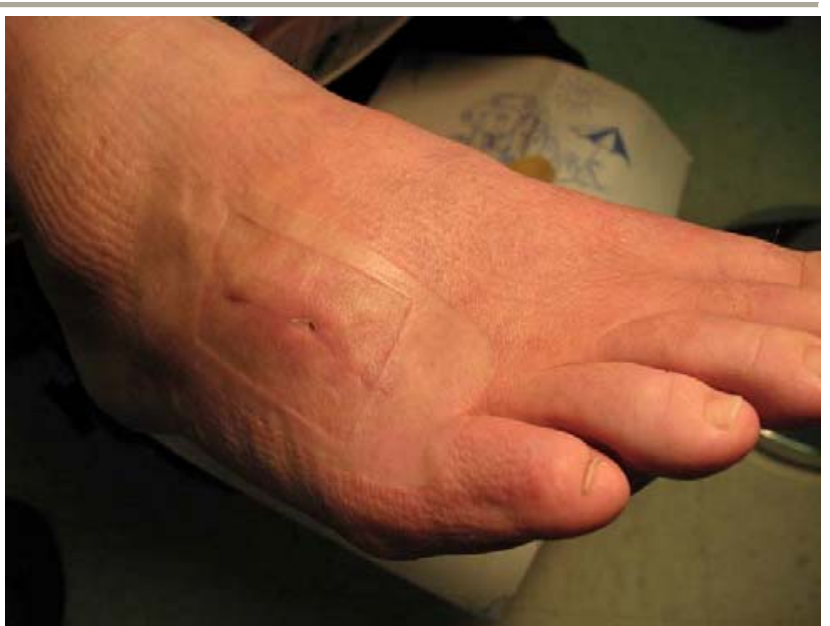

Figure 6 The wound is now closed and the patient has returned to work without incident.

In more serious lacerations, it is important to immediately control hemorrhage from the laceration by applying direct pressure to the wound. Applying a tourniquet to the extremity is not recommended because swelling and systemic effects are rare in extremity wounds. ${ }^{2}$ The wound should always be cleansed thoroughly with an antibacterial wound cleanser immediately after injury. Hexachlorophene in 70\% alcohol $\left(\mathrm{pHisoHex}{ }^{\circledR}\right)$ or Betadine solution will provide good antibacterial cleansing of the wound. ${ }^{6}$

Although there is no antidote or anti-venom, it has also been reported that direct injection of $1 \%$ lignocaine (or lidocaine) may have an antivenomous affect to the venom that remains in the wound. ${ }^{6}$ If the patient presents some time after injury to the emergency room with a hot, swollen foot, it is important to incise and open the puncture site, even if no barb is present. Intravenous antibiotic therapy is recommended until the cellulites has resolved. Hyperbaric oxygen in the treatment of stingray envenomation has also proved to be beneficial. ${ }^{4}$ 
Tetanus prophylaxis should also be current. Levofloxin or Levaquin is the drug of choice against Vibrio species and will cover Staphylococcus aureus and multi-drug, gramnegative organisms common to penetration injuries. Bactrim and Doxycyline are also good against Vibrio species, although the coverage is not as good for staph and strep species. ${ }^{3}$

Of course, antibiotic treatment can be tailored to the results of deep tissue samples taken at time of surgery to determine the infective organism. At time of surgery, it is recommended to inspect the wound for foreign material, remove any necrotic tissue, take deep tissue biopsy for culture and leave the wound packed open. Packing can include Betadine gauze or calcium alginate. Calcium alginate dressing or Kaltostat ${ }^{\circledR}$ has been reported to absorb toxin in one report. ${ }^{7}$

\section{Conclusion}

Stingrays belong the the class Chondrichthyes meaning cartilaginous fishes. These are usually docile creatures that only strike when provoked or feel threatened. In this case, medical treatment after initial injury was delayed which required surgical treatment and prolonged hospitalization. The delay in initial treatment caused progressive tissue necrosis and secondary infection after injury.

It is important to treat these injuries promptly. If the injury is not life-threatening, it is important to quickly cleanse the wound and submerge the foot in hot water to deactivate the tissue enzymes that cause pain and tissue necrosis. Ideally, medical treatment will consist of radiographs to eliminate the possibility of a barb that may remain in the wound. In the emergency room setting, the wound can be injected with 1\% lidocaine and lanced at the puncture site. The wound should then be aggressively irrigated with Betadine. A calcium alginate dressing can then be applied to the open wound and allowed to heal by secondary intention. Oral antibiotics with coverage for gram positive and negative organisms are prescribed at discharge.

\section{References}

1. Perkins, A.R., Morgan, S.S.: Poisoning, Envenomation and Trauma from Marine Creatures. American Family Physician, February, 2004 [Online]

2. Ganard, S. Stingray Injuries, Envenomation, and Medical Mangement. [Online article]

3. Meade, J.L. Stingray Envenomations, Emedicine article [Online]

4. Rocca, A.F. Hyperbaric Oxygen Therapy in the treatment of soft tissue necrosis resulting from a stingray puncture wound. Foot Ankle Int. 22 (4): 318-323, April 2001. PubMed]

5. Perkins, A.R., Morgan, S.S.: Poisoning, Envenomation and Trauma from Marine Creatures. American Family Physician, February, 2004 [Online]

6. Fenner, P.J. et al: Fatal and Non-Fatal Stingray Envenomation. Med Journal Australia : 151:621-625. 1989. $\underline{\mathrm{PDF}}$

7. Fenner, P.J.: Stingray Envenomation: A Suggested New Treatment. Med Journal Australia: 163: 665. 1995 [DF]

8. St. Petersburg Times [Online news wire], October, 2006. 